\title{
EFFICACY OF ACETIC ACID VERSUS CIPROFLOXACIN EARDROPS IN ACHIEVING DRY EARS IN CHRONIC SUPPURATIVE OTITIS MEDIA IN ADULT POPULATION OF ISLAMABAD, PAKISTAN: A NON-RANDOMIZED CONTROL TRIAL
}

\author{
Arslan Akhtar ${ }^{1}$, Syed Maisam Ali ${ }^{2}$, Syed Ali Naqi ${ }^{3}$, Tabassum Aziz ${ }^{4}$, Wajih-ud-din Shinwari ${ }^{5}$, Syed Faizan \\ Hassan Shah ${ }^{2}$ \\ ${ }^{1}$ Hazrat Bari Sarkar Medical College, Islamabad, ${ }^{2}$ Ayub Medical Complex, Abbottabad, ${ }^{3}$ sslamabad Medical \\ and Dental College, Islamabad, ${ }^{4}$ Holy Family Hospital, Rawalpindi, ${ }^{5}$ Pakistan Institute of Medical Sciences, \\ Islamabad, Pakistan
}

\begin{abstract}
Background: Chronic suppurative otitis media (CSMO) is an important cause of preventable hearing loss, particularly in developing world. The objective of this trial was to compare efficacy of $2 \%$ acetic acid versus $0.3 \%$ ciprofloxacin ear drops in achieving dry ears in CSMO in adult population of Islamabad, Pakistan.

Materials \& Methods: This trial was conducted at Department of ENT, HBS Medical College, Islamabad, Pakistan from March 2018 to February 2019. With alpha $5 \%$, beta $20 \%$ and power of study $80 \%$, sample size was calculated 47 for each group. All adult patients of CSOM, having ear discharge for more than three months were eligible. Patients with aural poly, external auditory canal pathology, ear malignancy, having mastoid surgery in preceding 12 months or having used antibiotics in last one week were excluded. Experimental group received $2 \%$ acetic acid, twice daily while control group received $0.3 \%$ ciprofloxacin eardrops twice daily. At two weeks, achievement of dry ears was noted. Sex and age in years were matching variables. Primary end point was achieving dry ears, which was compared between the two groups using McNemar chi-square test.
\end{abstract}

Results: Experimental group included 30 (63.8\%) men and 17 (36.2\%) women and control group included 32 (68\%) men and 15 (32\%) women. Mean age of experimental group 36 \pm 2.14 years was matching to the control group $36 \pm 2.59$ years. Dry ears were achieved in 35 (74.47\%) patients in experimental group and in 11 (23.40\%) patients in control group. The efficacy of $2 \%$ acetic acid was significantly higher than $0.3 \%$ ciprofloxacin eardrops in achieving dry ears $(p<0.0001)$ in CSMO.

Conclusion: The efficacy of $2 \%$ acetic acid was significantly higher than $0.3 \%$ ciprofloxacin eardrops in achieving dry ears in chronic suppurative otitis media in adult population of Islamabad, Pakistan.

KEY WORDS: Chronic suppurative otitis media; Middle ear; Tympanic membrane perforation; Eustachian tube, Quinolones; Ciprofloxacin; Acetic Acid.

This article may be cited as: Akhtar A, Ali SM, Naqi SA, Aziz T, Shinwari W, Shah SFH. Efficacy of acetic acid versus ciprofloxacin eardrops in achieving dry ears in chronic suppurative otitis media in adult population of Islamabad, Pakistan: a non-randomized control trial. Gomal J Med Sci 2019 Jul-Sep; 17 (3): 90-4. https://doi. org/10.46903/gjms/17.03.2007

\section{Corresponding Author:}

Dr. Syed Maisam Ali

Consultant, Department of ENT

Ayub Medical Complex

Abbottabad, Pakistan

E-mail: makazmee@hotmail.com

Date Submitted: 23-03-2019

Date Revised: $\quad$ 17-06-2019

Date Accepted: $\quad$ 29-06-2019

\section{INTRODUCTION}

Background: Chronic suppurative otitis media (CSOM) is "defined as a chronic inflammation of the middle ear and mastoid cavity, which presents with recurrent ear discharges or otorrhoea through a tympanic perforation." It usually follows one or more attacks of acute otitis media and is considered an important cause of preventable hearing loss. Globally it involves some 65-330 million people, including 60\% (39-200 million) with significant hearing impairment. It is responsible for approximately 28,000 deaths 
and a more than 2 million DALYs. Over $90 \%$ of these patients are living in South-east Asia, Western Pacific regions and African countries. ${ }^{1}$

WHO classified countries as per CSOM prevalence rates; countries with $>4 \%$ prevalence rates were labeled as having highest prevalence, which included Tanzania, India, Solomon Islands, Guam, Australian Aborigines and Greenland. Urgent public health interventions were recommended to cope with this massive public health problem. ${ }^{1}$

The overall global incidence is estimated to be nine per 100,000 persons. ${ }^{2}$

As per WHO estimates, CSOM prevalence was $5.4 \%$ in Indonesia (all ages), 15\% in Aboriginal Australian children and 2-4\% in Thailand, Philippines, Malaysia and Vietnam. ${ }^{3}$

In the United Kingdom, the incidence of active CSOM in the adult population has been shown as $0.6 \%$. A study from Israel study showed the annual incidence in children (up to age 15 years) as 39 patients per 100,000 population. ${ }^{4}$

CSOM is commonly associated with hearing impairment, disability and poor educational performance and may lead to fatal intracranial infections and acute mastoiditis, especially in developing communities. ${ }^{5}$ No population based survey was available for prevalence of CSMO in Pakistan.

Gupta, et al. ${ }^{6}$ from Gwalior, India for the period from Nov 2011 to Sep 2013, showed otorrhoea resolution in $84 \%(42 / 50)$ cases of CSOM (tubotympanic type) using $2 \%$ acetic acid versus $58 \%$ (29/50) using ciprofloxacin eardrops for 3 months and ciprofloxacin $500 \mathrm{mg}$ twice daily for 15 days at 3 months follow up. Here efficacy of antiseptic was superior to ciprofloxacin eardrops.

Macfadyen, et al. ${ }^{7}$ conducted a trial in 2002 in Kenya, using ciprofloxacin (Ciloxan 0.3\%; Alcon) eardrops and antiseptic eardrops (2\% boric acid in $45 \%$ alcohol) in school children twice daily. At two weeks follow up, dry ear was achieved in 123/207 (59.42\%) cases with ciprofloxacin eardrops while it was 65/204 $(31.86 \%)$ in antiseptic eardrops. Here efficacy of ciprofloxacin was superior to antiseptic eardrops.

Aminifarshidmehr $\mathrm{N}^{8}$ from Dubai, United Arab Emirates, used ear irrigation with $2 \%$ acetic acid solution three times per week and found dry ear in 55/96 $(57.29 \%)$ at three weeks follow up.

Onali, et al. ${ }^{9}$ noted resolution of ear discharge in $48 / 50(96 \%)$ patients of CSMO with topical ciprofloxacin, while it was $49 / 50(98 \%)$ in patients receiving oral plus topical ciprofloxacin.

In a randomized controlled trial, Loock JW ${ }^{10}$ in 2010 showed that ciprofloxacin eardrops achieved dry ears in $73 \%$ cases while $1 \%$ acetic acid eardrops achieved it in $24 \%$ cases of active chronic otitis media.
In a prospective double blind randomized trial in Vellore, India by Jaya, et al. ${ }^{11}$ from March to November $2000,0.3 \%$ ciprofloxacin eardrops three times daily for 10 days achieved dry ears at four weeks follow up in $90 \%$ (19/21) cases of CSOM (tubotympanic type).

1.2 Research Problem, Knowledge Gap \& Research Question: Unawareness of the difference between the efficacy of $2 \%$ acetic acid and $0.3 \%$ ciprofloxacin eardrops in achieving dry ears in chronic suppurative otitis media in adult population of Islamabad, Pakistan was our research problem. Absence of recent studies on this problem for our population on various databases/ search engines like PubMed, PubMed Central, ScienceDirect, ProQuest, Open Access Theses \& Dissertations, Pakistan Research Repository, Google Scholar and Google was our knowledge gap. Which one of these two has better efficacy in terms of achieving dry ears in CSOM was our research question. To fill this knowledge gap was the rationale/ justification of our trial.

Research Objective: The objective of this trial was to compare the efficacy of $2 \%$ acetic acid versus $0.3 \%$ ciprofloxacin eardrops in achieving dry ears in chronic suppurative otitis media in adult population of Islamabad, Pakistan.

Research (Null) Hypothesis $\left(\mathbf{H}_{0}\right)$ : The efficacy of $2 \%$ acetic acid and $0.3 \%$ ciprofloxacin eardrops is same in achieving dry ears in chronic suppurative otitis media in adult population of Islamabad, Pakistan.

\section{MATERIALS AND METHODS}

Design, Settings \& Duration: This non-randomized controlled trial was carried out at the Department of ENT, Hazrat Bari Sarkar (HBS) Medical College, Islamabad, Pakistan from March 2018 to February 2019. It was a parallel group design with post test only analysis. This trial was approved by the Institutional Ethical Review Committee. Informed consent for participating in the trial was taken from all the patients. The sample was collected from ENT outdoor of HBS Hospital; attached teaching hospital of the HBS Medical College.

Population, Sample Size, Technique \& Selection: The population of Islamabad, the capital city of $\mathrm{Pa}$ kistan was 1.015 million in 2017. Half million of this was estimated to be adult ( $>19$ years). With expected $2 \%$ prevalence of CSMO in this population, the population at risk was estimated to be 10,000 adult persons, from where we draw our sample, and on to which we will infer our sample results.

With two independent groups, binomial/ dichotomous primary end point, anticipated efficacy of $84 \%$ for experimental group \& $58 \%$ for control group, enrollment ratio of 1 , alpha $5 \%$, beta $20 \%$ and power of study $80 \%$, the sample size was calculated as 47 for each group through an online sample size calculator. ${ }^{12,13}$ 
All adult (>19 years) patients of CSOM, having ear discharge for more than three months were eligible for inclusion in this trial. In cases with bilateral CSOM, only one ear was selected for the trial. Patients having CSOM with aural poly, external auditory canal pathology, any existing ear malignancy, having had mastoid surgery in the preceding 12 months or having used antibiotics in the last one week were excluded.

Conduct of Procedure \& Intervention: All these patients were assessed initially through otorhinolaryngological \& general history and otoscopic, general physical \& systematic examination. Then these patients were assigned to two treatment/ intervention groups, each with 47 patients, placing odd numbers to experimental and even numbers to control group consecutively. Experimental group received $2 \%$ acetic acid, twice daily after aural mopping. The control group received $0.3 \%$ ciprofloxacin eardrops, six drops twice daily. At two weeks follow up, achievement of dry ears (yes/ no) was noted through otoscopy in each group.

Data Collection and Analysis: Sex (men/ women) and age in years were matching variables. The research variable/ primary end point was achieving dry ears (yes/no). Sex and achieving dry ears were nominal variables and were descriptively analyzed by count and percentage. Age in years was a numeric variable and was analyzed by mean and SD.

Based on sample statistics, estimated parameters as interval estimates for population are given as confidence interval $(\mathrm{Cl})$ for proportion at $90 \%$ confidence level for each group using an online statistical calculator. ${ }^{14}$

Achieving dry ears in experimental group was com- pared to control group using McNemar chi-square test at alpha 0.5 , using an online statistical calculator GraphPad..$^{15}$ This test is discussed by Zar $\mathrm{JH}^{16}$ and Pagano \& Gauvreau ${ }^{17}$ in their text books of statistics and recently applied and discussed in similar trial by Shah, et al. ${ }^{18,19}$

\section{RESULTS}

Total 94 patients were included in this trial with 47 patients in each group. Out of 47 patients in experimental group, 30 (63.8\%) were men and 17 (36.2\%) were women. Out of 47 patients in control group, $32(68 \%)$ were men and $15(32 \%)$ were women. The proportion of men to women in the two groups was matching. The mean age of experimental group $36 \pm 2.14$ years was matching to the mean age of control group $36 \pm 2.59$ years.

The single research variable/ primary end point of the trial (achieving dry ears) was 'yes' in 35 (74.47\%) patients in experimental group and in 11 (23.40\%) patients in control group. Estimated parameters for population are given as confidence interval $(\mathrm{Cl})$ for proportion at $90 \%$ confidence level for each group. (Table 1)

The efficacy in achieving dry ears in chronic suppurative otitis media in experimental group was compared to control group through McNemar chi-square test. With $p$-value of $<0.0001$ (less than alpha), the null hypothesis was proved to be false and hence rejected, showing statistically highly significant difference between the two groups in our population. In simple words, the efficacy of $2 \%$ acetic acid is significantly higher than $0.3 \%$ ciprofloxacin eardrops in achieving dry ears in chronic suppurative otitis media in adult population of Islamabad, Pakistan. (Table 2)

Table 1: Efficacy in experimental and control groups in achieving dry ears in chronic suppurative otitis media in adult population of Islamabad, Pakistan

\begin{tabular}{|l|c|c|c|c|c|c|c|c|}
\hline \multirow{2}{*}{$\begin{array}{l}\text { Dry ears } \\
\text { achieved }\end{array}$} & \multicolumn{4}{|c|}{ Experimental group (n1=47) } & \multicolumn{4}{c|}{ Control group (n2=47) } \\
\cline { 2 - 9 } & Sample Statistics & \multicolumn{2}{|c|}{$90 \%$ Cl for Proportion } & Sample Statistics & 90\% Cl for Proportion \\
\cline { 2 - 9 } & Count & \%age & Lower & Upper & Count & \%age & Lower & Upper \\
\hline Yes & 35 & 74.47 & 64.01 & 84.93 & 11 & 23.40 & 14.01 & 34.59 \\
\hline No & 12 & 25.53 & 15.07 & 35.99 & 36 & 76.60 & 66.44 & 86.76 \\
\hline Total & 47 & 100.00 & \multicolumn{2}{|c|}{ Population Parameters } & 47 & 100.00 & Population Parameters \\
\hline
\end{tabular}

Table 2: Comparison of efficacy in experimental versus control group in achieving dry ears in chronic suppurative otitis media in adult population of Islamabad, Pakistan

\begin{tabular}{|c|c|c|c|c|c|c|}
\hline \multirow{2}{*}{\multicolumn{2}{|c|}{ Groups }} & \multicolumn{2}{|c|}{ Experimental group $(\mathrm{n} 1=47)$} & \multirow{3}{*}{\begin{tabular}{|r|}
$\begin{array}{l}\text { Row } \\
\text { Totals }\end{array}$ \\
11
\end{tabular}} & \multirow[t]{2}{*}{$\chi^{2}$ value } & \multirow[t]{2}{*}{ P-value } \\
\hline & & Dry ears achieved & Dry ears not achieved & & & \\
\hline \multirow{3}{*}{ 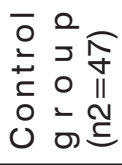 } & Dry ears achieved & 07 & 04 & & \multirow{2}{*}{16.531} & \multirow{2}{*}{$<0.0001$} \\
\hline & Dry ears not achieved & 28 & 08 & 36 & & \\
\hline & Column Totals & 35 & 12 & 47 Pairs & $\mathrm{H}_{0} \mathrm{re}$ & jected \\
\hline \multicolumn{3}{|c|}{ Yates continuity correction applied } & \multicolumn{4}{|c|}{ McNemar chi-square test at alpha 05 \& d.f. 1} \\
\hline
\end{tabular}




\section{DISCUSSION}

In this trial, we have identified the Research Problem, verified the Knowledge Gape, placed the Research Question, narrated the Research Objective and formulated the Research Hypothesis; the tentative answer. To testify the hypothesis, we collected the relevant data (Data Collection), analyzed the data (Data Analysis) and interpreted the data (Data Interpretation). This eight steps intellectual flow is termed as "Marwat's Logical Trajectory for Research Process," proposed by Marwat M. ${ }^{18,19}$

In this trial, we have identified our population of interest, drawn a sample, intervened and observed the sample for change in the variable of interest i.e. achievement of dry ears (sample statistics), inferred it on to the population as confidence interval for proportion (estimation of parameters) and then compared the experimental group to the control group to confirm statistically which intervention (treatment) is better for our population (hypothesis testing). ${ }^{18,19}$ Most of the authors start their projects with sample and end on the sample, with no mention of population. It is here in this project that we could not find trials for comparison with regard to population. Hence we have to compare our population parameters to sample statistics of all other trials/ studies given under discussion below.

In our trial, the experimental group ( $2 \%$ acetic acid) was matching to the control group ( $0.3 \%$ ciprofloxacin eardrops) by sex; the experimental group included $63.8 \%(30 / 47)$ men and $36.2 \%(17 / 47)$ women and the control group included 68\% (32/47) men and $32 \%(15 / 47)$ women. Also the mean age of the experimental group $36 \pm 2.14$ years was matching to the mean age of the control group $36 \pm 2.59$ years.

The primary end point of ours trial 'dry ears' was achieved in $74.47 \%$ (35/47) (90\% CL 64.01-84.93) patients in experimental group (2\% acetic acid) and in $23.40 \%$ (11/47) $(90 \%$ CL 14.01-34.59) patients in control group (0.3\% ciprofloxacin eardrops). The efficacy of $2 \%$ acetic acid was significantly higher than $0.3 \%$ ciprofloxacin eardrops ( $p$-value $<0.0001$ ) in achieving dry ears in chronic suppurative otitis media in adult population of Islamabad, Pakistan.

Similar results are shown by Gupta, et al. ${ }^{6}$ from Gwalior, India for the period from Nov 2011 to Sep 2013, where otorrhoea resolution was seen in $84 \%(42 / 50)$ cases of CSOM (tubotympanic type) using $2 \%$ acetic acid versus $58 \%$ (29/50) using ciprofloxacin eardrops for 3 months and ciprofloxacin $500 \mathrm{mg}$ twice daily for 15 days at 3 months follow up. Here efficacy of antiseptic was superior to ciprofloxacin eardrops.

Opposing to our results are noted by Macfadyen, et al. ${ }^{7}$ in a trial in 2002 in Kenya, using ciprofloxacin (Ciloxan 0.3\%; Alcon) eardrops and antiseptic eardrops ( $2 \%$ boric acid in $45 \%$ alcohol) in school children twice daily. At two weeks follow up, dry ear was achieved in 123/207 (59.42\%) cases with ciprofloxacin eardrops while it was 65/204 (31.86\%) in antiseptic eardrops. Here efficacy of ciprofloxacin was superior to antiseptic eardrops.

Lower efficacy than ours trial for $2 \%$ acetic acid solution is shown by Aminifarshidmehr $\mathrm{N}^{8}$ from Dubai, United Arab Emirates, who used ear irrigation with $2 \%$ acetic acid solution three times per week and found dry ear in 55/96 (57.29\%) at three weeks follow up.

Higher than ours trial are results for topical ciprofloxacin by Onali, et al. ${ }^{9}$ who noted resolution of ear discharge in 48/50 (96\%) patients of CSMO with topical ciprofloxacin, while it was $49 / 50(98 \%)$ in patients receiving oral plus topical ciprofloxacin.

Opposing to our trial are results from a randomized controlled trial by Loock JW' ${ }^{10}$ in 2010 , which showed that ciprofloxacin eardrops achieved dry ears in $73 \%$ cases while $1 \%$ acetic acid eardrops achieved it in $24 \%$ cases of active chronic otitis media. Here ciprofloxacin eardrops showed better efficacy than $1 \%$ acetic acid eardrops.

Better efficacy than ours trial for $0.3 \%$ ciprofloxacin eardrops is given by a prospective double blind randomized trial in Vellore, India by Jaya, et al. ${ }^{20}$ from March to November 2000, where $0.3 \%$ ciprofloxacin eardrops three times daily for 10 days achieved dry ears at four weeks follow up in $90 \%$ (19/21) cases of CSOM (tubotympanic type).

\section{CONCLUSION}

The efficacy of $2 \%$ acetic acid was significantly higher than $0.3 \%$ ciprofloxacin eardrops in achieving dry ears in chronic suppurative otitis media in adult population of Islamabad, Pakistan.

Acknowledgement: Dr. Muhammad Marwat from Gomal Medical College, D.I.Khan, Pakistan is highly acknowledged for organizing our manuscript in an innovative format in the light of his eight steps "Marwat's Logical Trajectory for Research Process". He also conducted the advanced statistical analysis for this project.

\section{REFERENCES}

1. Chronic Suppurative Otitis media: burden of illness and management options. Child and Adolescent Health and Development, Prevention of Blindness and Deafness. World Health Organization. Geneva, Switzerland: 2004; 14-9.

2. Morris P. Chronic Suppurative Otitis media. Am Fam Physician. 2013 Nov 15; 88(10):694-696. Available at: https://www.aafp.org/afp/2013/1115/ p694.pdf

3. Mahadevan M, Navarro-Locsin G, Tan HK, Yamanaka N, Sonsuwan N, Wang PC, et al. Int J Pediatr Otorhinolaryngol 2012 May;76(5):623-35. https://doi.org/10.1016/j.ijporl.2012.02.031

4. Preciado DA. Inflammatory Diseases of the Mid- 
dle Ear. Epidemiology. [updated 2018 Jun 18, accessed 2018 March 9]. Medscape, New York. Available at: https://emedicine.medscape.com/ article/860227-overview\#a6

5. Acuin J. Chronic suppurative otitis media. BMJ Clin Evid 2007 Feb 1;2007:0507. Available at: https://www.ncbi.nlm.nih.gov/pmc/articles/ PMC2943814/

6. Gupta C, Agarwal A, Gargav ND. Role of acetic acid irrigation in medical management of chronic suppurative otitis media: A comparative study. Indian J Otolaryngol Head Neck Surg 2015 Jul-Sep;67(3):314-8. https://doi.org/10.1007/ s12070-014-0815-2

7. Macfadyen C, Gamble C, Garner P, Macharia I, Mackenzie I, Mugwe P, et al. Topical quinolone vs. antiseptic for treating chronic suppurative otitis media: a randomized controlled trial. Trop Med Int Health 2005;10(2):190-7. https://doi. org/10.1111/j.1365-3156.2004.01368.x

8. Aminifarshidmehr $\mathrm{N}$. The management of chronic suppurative otitis media with acid media solution. Am J Otol. 1996 Jan 1;17(1):24-5.

9. Onali MA, Bareeqa SB, Zia S, Ahmed SI, Owais A, Ahmad AN. Efficacy of empirical therapy with combined ciprofloxacin versus topical drops alone in patients with tubotympanic chronic suppurative otitis media: A randomized double- blind controlled trial. Clin Med Insights Ear Nose Throat 2018 Jan 11. https://doi. org/10.1177/1179550617751907

10. Loock JW. A randomized controlled trial of active chronic otitis media comparing courses of eardrops versus one- off topical treatments suitable for primary, secondary and tertiary health care settings. Clin Otolaryngol 2012 Aug;37 (4):261-70. https://doi.org/10.1111/j.1749-4486.2012.02532.x

11. C Jaya, Anand Job, Elizabeth Mathai, B Antonisamy. Evaluation of topical povidone-iodine in chronic suppurative otitis media. Arch Otolaryngol
Head Neck Surg 2003;129:1098-1100. https://doi. org/10.1001/archotol.129.10.1098

12. Rosner B. Fundamentals of Biostatistics. 7th ed. Boston, MA: Brooks/Cole; 2011.

13. Kane SP. Sample Size Calculator. ClinCalc [internet]. Chicago, IL, USA. [accessed 2018 Jan 17]. Available at: https://clincalc.com/stats/ samplesize.aspx

14. Statistics Kingdom. Proportion confidence interval calculator [internet]. Statistics Kingdom; Melbourne, Australia 2007. [accessed 2019 Mar 12]. Available at: http://www.statskingdom. com/41_proportion_confidence_interval.html

15. Motulsky HJ. GraphPad, QuickCalcs. McNemar's test to analyze experimental studies. GraphPad Software, San Diego, CA, USA. [accessed 2018 2019 Mar 12]. Available at: https://www.graphpad. $\mathrm{com} /$ quickcalcs/McNemar1.cfm

16. Zar JH. Biostatistical Analysis. 5th ed. New York: Prentice-Hall, Inc. pp.127.

17. Pegano M, Gauvreau K. Principals of Biostatistics. 2nd ed. Boston, MA, USA: Cengage Learning; 2000. pp.349-52.

18. Shah HU, Gul H, Khan R, Marwat M. Urethrocutaneous fistula following Snodgrass versus two stage Aivar Bracka repair of distal penile hypospadias in male children: a randomized control trial. Gomal J Med Sci 2018 Apr-Jun;16 (2):54-8. https://doi.org/10.46903/gjms/16.02.1284

19. Shah S, Basharat A, Shah M, Marwat M, Billah M, Ali SM. Frequency, distribution and presentation of hypocalcemia in B-thalassemia major. Gomal J Med Sci 2018 Jan-Mar;16(1):2-8. https://doi. org/10.46903/gjms/16.01.1446

20. C Jaya, Anand Job, Elizabeth Mathai, B Antonisamy. Evaluation of topical povidone-iodine in chronic suppurative otitis media. Arch Otolaryngol Head Neck Surg 2003;129:1098-1100. https://doi. org/10.1001/archotol.129.10.1098

$$
\begin{gathered}
\text { CONFLICT OF INTEREST } \\
\text { Authors declare no conflict of interest. } \\
\text { GRANT SUPPORT AND FINANCIAL DISCLOSURE } \\
\text { None declared. }
\end{gathered}
$$

\section{AUTHORS' CONTRIBUTION}

The following authors have made substantial contributions to the manuscript as under:

Conception or Design:

Acquisition, Analysis or Interpretation of Data:

Manuscript Writing \& Approval:

All the authors agree to be accountable for all aspects of the work in ensuring that questions related to

the accuracy or integrity of any part of the work are appropriately investigated and resolved. 